\title{
The modulatory effect of Moringa oleifera leaf extract on endogenous antioxidant systems and inflammatory markers in acetaminophen-induced nephrotoxic mice model
}

Govindarajan Karthivashan, Aminu Umar Kura, Palanisamy Arulselvan, Norhaszalina Md. Isa, Sharida Fakurazi

$\mathrm{N}$-Acetyl-p-Aminophenol (APAP), aka acetaminophen, is the most commonly used over-the counter analgesic and antipyretic medication. However, its overdose leads to both liver and kidney damage. APAP-induced toxicity is considered as one of the primary causes of acute liver failure; numerous scientific reports have focused majorly on APAP hepatotoxicity. Alternatively, not many works approach APAP nephrotoxicity focusing on both its mechanisms of action and therapeutic exploration. Moringa oleifera (MO) is pervasive in nature and is reported to possess surplus amount of nutrients, and is enriched with several bioactive candidates including trace elements that act as curatives for various clinical conditions. In this study, we evaluated the nephro-protective potential of MO leaf extract against APAP nephrotoxicity in male Balb/c mice. A single-dose acute oral toxicity design was implemented in this study. Group 2, 3, 4 and 5 received a toxic dose of APAP (400 mg/kg of bw, i.p) and after an hour, these groups were administered with saline (10 $\mathrm{mL} / \mathrm{kg}$ ), silymarin - positive control (100 mg/kg of bw, i.p), MO leaf extract (100 mg/kg of bw, i.p), and MO leaf extract (200 mg/kg bw, i.p) respectively. Group 1 was administered saline $(10 \mathrm{~mL} / \mathrm{kg}$ ) during both the sessions. APAP-treated mice exhibited a significant elevation of serum creatinine, blood urea nitrogen, sodium, potassium and chloride levels. A remarkable depletion of antioxidant enzymes such as SOD, CAT and GSH-Px with elevated MDA levels has been observed in APAP treated kidney tissues. They also exhibited a significant raise in pro-inflammatory cytokines (TNF- $\alpha, \mathrm{IL}-1 \beta, \mathrm{IL}-6)$ and decreased anti-inflammatory (IL-10) cytokine level in the kidney tissues. Disorganized glomerulus and dilated tubules with inflammatory cell infiltration was clearly observed in the histology of APAP treated mice kidneys. All these pathological changes were reversed in a dose dependent manner after MO leaf extract treatment. Therefore, MO leaf extract has demonstrated some therapeutic effectiveness against APAP-induced nephrotoxicity through enhancement of endogenous antioxidant system and modulatory effect on specific inflammatory cytokines in kidney tissues. 
1 THE MODULATORY EFFECT OF MORINGA OLEIFERA LEAF EXTRACT ON

2 ENDOGENOUS ANTIOXIDANT SYSTEMS AND INFLAMMATORY MARKERS IN

3 ACETAMINOPHEN-INDUCED NEPHROTOXIC MICE MODEL

4 Govindarajan Karthivashan ${ }^{1}$, Aminu Umar Kura ${ }^{1}$, Palanisamy Arulselvan ${ }^{1}$, Norhaszalina Md.

$5 \quad$ Isa $^{1},{ }^{\dagger}$ Sharida Fakurazi ${ }^{1,2}$.

6 Short Title: Nephroprotective role of Moringa leaves

$7{ }^{1}$ Laboratory of Vaccines and Immunotherapeutics, Institute of Bioscience, Universiti Putra Malaysia, 43400,

8 Serdang, Selangor, Malaysia.

92 Department of Human Anatomy, Faculty of Medicine and Health Sciences, Universiti Putra Malaysia, 43400,

10 Serdang, Selangor, Malaysia.

$\dagger$ Correspondence:

Dr. Sharida Fakurazi, Ph.D.,

Associate Professor and Head of the Laboratory

Department of Human Anatomy, Faculty of Medicine and Health Sciences, and

Laboratory of Vaccines and Immunotherapeutics, Institute of Bioscience,

Universiti Putra Malaysia, 43400 UPM Serdang, Selangor, Malaysia.

Tele: +603 8947 2331; Fax: +603 89422341.

E-mail: sharida@upm.edu.my; sharida.fakurazi@gmail.com 
27 ABSTRACT

28 N-Acetyl-p-Aminophenol (APAP), aka acetaminophen, is the most commonly used over-the counter analgesic and antipyretic medication. However, its overdose leads to both liver and kidney damage. APAP-induced toxicity is considered as one of the primary causes of acute liver failure; numerous scientific reports have focused majorly on APAP hepatotoxicity. Alternatively, not many works approach APAP nephrotoxicity focusing on both its mechanisms of action and therapeutic exploration. Moringa oleifera (MO) is pervasive in nature and is reported to possess surplus amount of nutrients, and is enriched with several bioactive candidates including trace elements that act as curatives for various clinical conditions. In this study, we evaluated the nephro-protective potential of MO leaf extract against APAP nephrotoxicity in male Balb/c mice. A single-dose acute oral toxicity design was implemented in this study. Group 2, 3, 4 and 5 received a toxic dose of APAP (400 mg/kg of bw, i.p) and after an hour, these groups were administered with saline (10 mL/kg), silymarin - positive control (100 mg/kg of bw, i.p), MO leaf extract (100 mg/kg of bw, i.p), and MO leaf extract (200 mg/kg bw, i.p) respectively. Group 1 was administered saline $(10 \mathrm{~mL} / \mathrm{kg})$ during both the sessions. APAP-treated mice exhibited a significant elevation of serum creatinine, blood urea nitrogen, sodium, potassium and chloride levels. A remarkable depletion of antioxidant enzymes such as SOD, CAT and GSH-Px with elevated MDA levels has been observed in APAP treated kidney tissues. They also exhibited a significant raise in pro-inflammatory cytokines (TNF- $\alpha$, IL-1 $\beta$, IL-6) and decreased antiinflammatory (IL-10) cytokine level in the kidney tissues. Disorganized glomerulus and dilated tubules with inflammatory cell infiltration was clearly observed in the histology of APAP treated mice kidneys. All these pathological changes were reversed in a dose dependent manner after MO leaf extract treatment. Therefore, MO leaf extract has demonstrated some therapeutic 
50 effectiveness against APAP-induced nephrotoxicity through enhancement of endogenous

51 antioxidant system and modulatory effect on specific inflammatory cytokines in kidney tissues.

52 Abbreviations: MO - Moringa oliefera; APAP - acetaminophen; GSH-Px- glutathione 53 peroxidase; SOD - superoxide dismutase; CAT - catalase; MDA - Malondialdehyde; NAPQI 54 N-acetyl-p-benzoquinoneimine; TNF- $\alpha$ - Tumor necrosis factor- $\alpha$; IL - Interleukin; NAC-N55 acetylcysteine.

56

57

58

59

60

61

62

63

64

65

66

67 


\section{1. INTRODUCTION}

Acetaminophen (APAP) is a readily available over-the-counter medication as an effective painkiller and fever suppressor. APAP retains a virtuous safety profile at therapeutic doses. However, when its therapeutic index is breached, it results in acute / chronic hepato-renal damage in both human and experimental animals (Ghosh et al. 2010, Karthivashan et al. 2015a, Karthivashan et al. 2015b). Though the incident rate of APAP hepatotoxicity is higher than the renal toxicity, the latter leads to $1-2 \%$ of acute renal failure in patients with APAP overdose and can be fatal (Eguia \& Materson 1997). The pathophysiology of APAP-induced nephrotoxicity is not much explored compared to APAP hepatotoxicity. Based on previous literature they both allegedly expressed a similar kind of pathophysiology, yet some subtle differences were observed, and remain indistinct (Li et al. 2003, Cekmen et al. 2009, Aycan et al. 2015).

The most probable mechanism of APAP nephrotoxicity involves the metabolic activation of the reactive toxic metabolite, N-acetyl-p-benzoquinone imine (NAPQI). At therapeutic doses, only a few percent of APAP gets converted to the reactive toxic metabolite NAPQI, which is further reduced by glutathione and subsequently excreted as glucuronidated and sulfated (nontoxic) hydrophilic metabolites through the renal system. In an APAP overdose, the supply of sulfate and glutathione get exhausted, thus more NAPQI is generated via CYP450 metabolism. This electrophilic intermediary binds with available cellular proteins and initiate lipid peroxidation, mediated reactive oxygen species (ROS) and other free radical formation, thereby inducing oxidative stress and inflicting renal tissue damage (Isik et al. 2006, Ahmad et al. 2012). This cascade furthermore provokes inflammatory signals and extended the injury, resulting in tubular cell-death / acute renal failure (Möller-Hartmann \& Siegers 1991). Due to its fatal nature, the requirement of an antidote / therapeutic agent against APAP renal toxicity becomes crucial. 
91 N-acetylcysteine (NAC), a precursor of GSH, is well known for its hepato-protective nature 92 against APAP-induced hepatotoxicity in both humans and animals; however, it has a limited 93 function towards APAP-induced renal toxicity (Eguia \& Materson 1997, Mazer \& Perrone 94 2008). Thus, the hunt for alternative, safe and therapeutically effective compounds against 95 APAP-induced renal toxicity is essential.

Moringa oleifera Lam (MO) is a wide-spread tropical and subtropical species belongs to

Moringaceae family. It is well known for its remarkable nutritional value and elite therapeutic potential against extensive clinical conditions. Moringa oleifera Lam is commonly known as "drumstick tree" or "horseradish tree" and almost all parts of this plant, including the root, bark, stem, leaves, flowers and pods possess huge amounts of micro- and macronutrients. It provides, both animal and human nutritional supplements (Siddhuraju \& Becker 2003, Anwar et al. 2007). It possesses a rich and rare combination of therapeutically-active candidates such as kaempferol, rhamnetin, quercitin, chlorogenic acid, rutin, and apigenin, and is also enriched with an exogenous supply of ascorbic acid and carotenoids, which are renowned antioxidant candidates (Anwar et al. 2007, Karthivashan et al. 2013). MO has been utilized for ages as traditional medicine in the treatment of numerous disorders as an antiseptic, anti-diabetic, antiepileptic, antiparalytic, antiviral, anti-inflammatory effect. Additionally, numerous scientific reports on various parts of the plant have reported on its medicinal value, among which its leaves has been extensively studied in a wide variety of clinical conditions for antimicrobial, anti-inflammatory, anti-cancer, and anti-diabetic effects (Anwar et al. 2007). Our research team has recently identified that flavonoids such as kaempferol, quercitin and apigenin were likely involved in the

112 enhanced antioxidant effect of MO leaves extract, and further established its hepatoprotective 
113 mechanism of action against APAP-induced hepatotoxicity (Karthivashan et al. 2015b,

114 Karthivashan et al. 2013).

115 In, recent years, it has been established that the existence of trace elements in MO leaf

116 extract also contributes to improvising human health and combating various health disorders

117 (Gowrishankar et al. 2010, Prashanth et al. 2015). Thus, in this study, we evaluated several

118 essential / non-essential trace elements of MO leaf extract to investigate their possible

119 involvement against APAP toxicity. The pathophysiology of APAP-induced hepatotoxicity is

120 proposed to be similar to that of APAP nephrotoxicity; thus, here we extended our investigation

121 on the potential nephro-protective mechanism of MO leaf extract against APAP-induced

122 nephrotoxicity. Furthermore, silymarin has been selected as the positive control for this study,

123 based on previous study reports due to its enhanced hepato- and renal-protective properties

124 against APAP toxicity in mice due to its enriched antioxidative and anti-inflammatory nature (He

125 et al. 2004, Bektur et al. 2013). This would pave way for further investigation on the

126 advancement of MO leaf extract as an effective therapy for both APAP-induced nephro- and

127 hepato-toxicity in the field of clinical / translational medication.

128

129

\section{MATERIALS AND METHODS}

\subsection{Chemicals}

131 Acetaminophen and silymarin were procured from Sigma (St. Louis, MO, USA). All

132 kidney function markers kits, malondialdehyde (MDA) and antioxidant enzyme assay kits were 133 purchased from Roche Diagnostics (Germany), Biovision Research kits (CA, USA) and Cayman 134 chemical company (Ann Arbor, MI, USA) respectively. HEPES buffer was obtained from 135 Nacalai Tesque (Kyoto, Japan). Porcelain crucible, analytical balance (OHAUS, made in 
136 Switzerland), oven (Genlab, UK), type 1500 furnace, desiccators, and Solaar M atomic 137 absorption spectrometer (AAS) (Thermo Elemental, USA) were used for AAS analysis. All 138 glassware used was rinsed and soaked in $10 \%$ (v/v) $\mathrm{HNO}_{3}$ overnight. They were rinsed with de139 ionized water and dried before use. All other chemicals and reagents used were obtained from 140 Sigma (St. Louis, MO, USA) unless indicated otherwise

\section{$141 \quad 2.2 \quad$ Plant materials}

142 Fresh mature leaves from the Moringa oliefera tree were harvested from Garden-2, Universiti 143 Putra Malaysia (UPM) and have been confirmed similar to the voucher specimen (SK 1561/08) 144 previously deposited in the Institute of Bioscience, UPM (IBS) Herbarium unit. The whole plant

145 leaves were collected, washed in running tap water, air dried at room temperature $\left(24{ }^{\circ} \mathrm{C}\right)$ for a 146 day and oven dried for two consecutive days at $45^{\circ} \mathrm{C}$. The dried plant material was ground using 147 a mechanical blender and stored in an airtight container after processing.

\section{$148 \quad 2.3 \quad$ Preparation of leaf extract}

149 The Moringa oleifera leaf powder was macerated exhaustively with $90 \%$ ethanol (ethanol: 150 distilled water, 90:10) in aspirator bottle for 3 consecutive days at room temperature with 151 continuous shaking. The residue was strained and the filtrate was condensed using a rotary 152 evaporator at $40{ }^{\circ} \mathrm{C}$. The condensed residue was of slurry nature and dark green in color, which 153 were further freeze-dried. The obtained freeze-dried extracts were weighed, kept in a capped 154 container, labeled appropriately and stored at $-20^{\circ} \mathrm{C}$.

$155 \quad 2.4 \quad$ Preliminary analysis of trace elements

156 2.4.1 Sample digestion - Dry ashing method

157 One gram of MO leaf extract was placed in a porcelain crucible in a furnace. The furnace 158 temperature was steadily increased from room temperature to $350{ }^{\circ} \mathrm{C}$. The sample turned to ash 
159 after 4 hours and the process continued until whitish grey ash residue was attained. The residue 160 was dissolved in $5 \mathrm{ml}$ of nitric oxide and increased to $10 \mathrm{~mL}$ volume in appropriate volumetric 161 flask.

\section{$162 \quad$ 2.4.2 Determination of trace elements}

163 In this study, we evaluated three essential trace elements; Copper (Cu), Manganese (Mn), Nickel $164(\mathrm{Ni})$, and three toxic trace elements; Cromium $(\mathrm{Cr})$, Lead $(\mathrm{Pb})$ and Cadmium $(\mathrm{Cd})$ present in the 165 MO leaf extract. Working standard solutions of appropriate elements were prepared from stock 166 standard solution (1000 mg/L) and absorbance values were obtained for various working 167 standards for each element in the samples, using an atomic absorption spectrometer (AAS). The absorbance values were plotted against concentration, whereby the formed linear calibration

169 curves revealed the actual concentration of the sample. A blank reading was also taken and essential correction was made during the calculation of concentration of various elements.

\section{$171 \quad 2.5 \quad$ Animals and experimental design}

172 Male Balb/c mice of 25 - $30 \mathrm{~g}$ weight (10-12 weeks old) were handled at the Animal House Unit, 173 Faculty of Medicine, Universiti Putra Malaysia (UPM). Animals were acclimatized for a week at $17426 \pm 2{ }^{\circ} \mathrm{C}$ with a $12 \mathrm{~h}$ light/dark cycle. Free access to food and water was allowed at all times.

175 During the acclimatization period, five mice were housed per cage in plastic cages using 176 homogenized wood shavings as bedding. All experimental protocols used on the animals were 177 done with the approval (UPM/IACUC/AUP-17/2013) and standard ethical guidelines of the 178 Faculty of Medicine and Health Sciences, Universiti Putra Malaysia, Malaysia, IACUC 179 (Institutional Animal Care and Use Committee) were followed.

A single-dose acute oral toxicity design was performed on Balb/c mice in this study. On 181

Day 8 , following acclimatization, the mice were randomly assigned into five groups $(n=6$ per 
182 group) with same housing setup. The APAP was dissolved in an appropriate concentration in

183 warm saline. Group 2, 3, 4 and 5 received a toxic dose of APAP (400 mg/kg of bw, i.p) followed

184 by administration of saline $(10 \mathrm{~mL} / \mathrm{kg})$, silymarin $(100 \mathrm{mg} / \mathrm{kg}$ of bw, i.p), MO leaf extract (100

$185 \mathrm{mg} / \mathrm{kg}$ of bw, i.p) and MO leaf extract $(200 \mathrm{mg} / \mathrm{kg}$ bw, i.p) respectively, an hour after the

186 administration of APAP lethal dose. Group 1 was administered saline $(10 \mathrm{~mL} / \mathrm{kg})$ during the two

187 sessions. The animals were sacrificed using diethyl ether about $24 \mathrm{~h}$ after induction of APAP

188 toxicity and subsequent treatment with the respective doses of silymarin /MO extract. Blood

189 samples were rapidly obtained by cardiac puncture, and serum was prepared and stored at -20

$190{ }^{\circ} \mathrm{C}$. The kidney was collected, snap-frozen and stored immediately at $-80{ }^{\circ} \mathrm{C}$ and a portion of

191 them was fixed at $10 \%$ buffered formalin.

$192 \quad$ 2.6 Biochemical parameters

193 All biochemical assays were performed spectrophotometrically using a Hitachi-912

194 Autoanalyser (Mannheim, Germany) with kits supplied by Roche Diagnostics (Mannheim,

195 Germany). Indicators of kidney function, including serum creatinine, urea, sodium $\left(\mathrm{Na}^{+}\right)$,

196 potassium $\left(\mathrm{K}^{+}\right)$, and chloride $\left(\mathrm{Cl}^{-}\right)$levels were measured. In order to obtain data with good

197 sensitivity and validity, serum samples were analyzed blindly and in triplicate.

\section{$198 \quad 2.7 \quad$ Histopathological examination}

199 Renal tissues from each group were fixed in $10 \%$ formalin and fixed samples were embedded in

200 paraffin, sectioned in $5 \mu \mathrm{m}$-thick sections and stained with hematoxylin-eosin (H\&E) stain. All

201 the pathological changes in renal tissues were examined and photographed using an Olympus

202 microscope (BX-51; Olympus, Tokyo, Japan).

$203 \quad 2.8 \quad$ Measurement of kidney oxidative stress and inflammatory markers 
204 The frozen renal tissue was thawed and homogenized in $10 \%(\mathrm{w} / \mathrm{v})$ with ice-cold $0.1 \mathrm{M}$

205 phosphate buffer saline and centrifuged at $9000 \mathrm{rpm}$ for $20 \mathrm{~min}$ at $4{ }^{\circ} \mathrm{C}$, and the supernatants

206 were assayed according to the instructions provided by the manufacturer. BioVision Research

207 kits (CA, USA) were used to determine the MDA level, and the activity of anti-oxidant enzymes

208 were determined using SOD, CAT and GPx kits obtained from the Cayman Chemical Company

209 (Ann Arbor, U.S.A). The levels of pro-inflammatory (TNF- $\alpha$, IL-1 $\beta$, IL-6) and anti-

210 inflammatory (IL-10) cytokines in renal tissue homogenates were determined using

211 commercially available ELISA kits, in accordance with manufacturers' instructions (R\&D,

212 Mannheim, Germany).

\section{$213 \quad 2.9 \quad$ Statistical analysis}

214 The results are expressed as mean \pm SEM. The normal distribution of the data was confirmed by

215 Shapiro-Wilk test using GraphPad software 5.0 (GraphPad, La Jolla, CA). Statistical analyses,

216 such as one-way ANOVAs and associated Student $t$-tests were performed for the biochemical,

217 oxidative stress and inflammatory parameters using Excel software (Microsoft, Redmond, WA).

218 A $p$-value less than 0.05 considered as statistically significant.

$219 \quad$ 3. $\quad$ RESULTS

2203.1 Trace elements of MO leaf extract

221 The MO leaf extract were found to contain various trace elements, which aid numerous

222 biochemical processes in the human body. In the present study, six trace elements, namely $\mathrm{Cu}$,

$223 \mathrm{Mn}, \mathrm{Ni}, \mathrm{Cr}, \mathrm{Pb}$ and $\mathrm{Cd}$ were determined with substantial accuracy. The concentration of each

224 element was determined, and the corresponding linear calibration curves were obtained and are

225 reported in Table 1, with their biochemical functions. The dried MO leaf extract contain high 
226 amount of Manganese $(\mathrm{Mn})$ and Copper $(\mathrm{Cu})$ with the value of $36.157 \pm 0.037$ and $12.323 \pm$

$2270.098 \mathrm{mg} / \mathrm{kg}$ of dry leaf extract, respectively compare to Nickel (Ni) with the value of $1.657 \pm$

$2280.008 \mathrm{mg} / \mathrm{kg}$ of dry leaf extract. Toxic trace elements such as Chromium $(\mathrm{Cr})$, Cadmium $(\mathrm{Cd})$

229 and Lead $(\mathrm{Pb})$ were expressed in a negligible amount, which was found to be less than 0.005

$230 \mathrm{mg} / \mathrm{kg}$ of dry leaf extract.

$231 \quad 3.2$ MO leaf extract minimizes APAP-induced nephrotoxicity in mice

232 The serum obtained from mice treated with toxic dose of APAP revealed significant $(p<0.05)$

233 elevation in creatinine $(0.51 \pm 0.02 \mathrm{mg} / \mathrm{dL})$, blood urea nitrogen $(42.0 \pm 2.0 \mathrm{mg} / \mathrm{dL})$, sodium

$234\left(\mathrm{Na}^{+} ; 142.20 \pm 0.35 \mathrm{mEq} / \mathrm{L}\right)$ potassium $\left(\mathrm{K}^{+} ; 12.30 \pm 0.24 \mathrm{mEq} / \mathrm{L}\right)$, and chloride $\left(\mathrm{Cl}^{-} ; 106.80 \pm\right.$

$2350.84 \mathrm{mEq} / \mathrm{L})$ levels, compare to the control group which displayed the following values:

236 creatinine $(0.25 \pm 0.01 \mathrm{mg} / \mathrm{dL})$, blood urea nitrogen $(19.60 \pm 1.4 \mathrm{mg} / \mathrm{dL})$, sodium $\left(\mathrm{Na}^{+} ; 138.10 \pm\right.$

$2370.45 \mathrm{mEq} / \mathrm{L})$ potassium $\left(\mathrm{K}^{+} ; 11.10 \pm 0.16 \mathrm{mEq} / \mathrm{L}\right)$ and chloride $\left(\mathrm{Cl}^{-} ; 103.70 \pm 1.08 \mathrm{mEq} / \mathrm{L}\right)$

238 Mice treated with MO extract had lowered levels of serum creatinine, blood urea nitrogen, $\mathrm{Na}^{+}$,

$239 \mathrm{~K}^{+}$, and $\mathrm{Cl}^{-}$compared to the groups that were not treated with $\mathrm{MO}$, and the reduction was found

240 to be dose-dependent. Among the adapted two doses of MO leaf extract, mice treated with 200

$241 \mathrm{mg} / \mathrm{kg}$ of bw displayed significant $(p<0.05)$ decrease in serum kidney biomarkers with the

242 values of creatinine $(0.29 \pm 0.04 \mathrm{mg} / \mathrm{dL})$, blood urea nitrogen $(30.8 \pm 1.0 \mathrm{mg} / \mathrm{dL})$, sodium

$243\left(\mathrm{Na}^{+} ; 140.20 \pm 0.18 \mathrm{mEq} / \mathrm{L}\right)$, potassium $\left(\mathrm{K}^{+} ; 11.30 \pm 0.12 \mathrm{mEq} / \mathrm{L}\right.$ and chloride $\left(\mathrm{Cl}^{-} ; 104.0 \pm 0.42\right.$

$244 \mathrm{mEq} / \mathrm{L}$ and it proximate the effects of the silymarin treated (positive control) group (Fig. 1A-E).

245 The histological micrographs of APAP intoxicated mice kidney sections portrayed

246 further, renal tissue damage by exhibiting severely disorganized glomerulus, dilated tubules,

247 presence of granular casts and inflammatory cell infiltrates (Fig. 4B1). Histological analysis of

$248 \mathrm{MO}(100 \mathrm{mg} / \mathrm{kg}$ bw) treated mice kidney sections showed some sparsely disorganized 
249 glomerulus, tubular dilation with moderate tubular casting and inflammation (Fig. 4C1).

250 However at a higher dose of $200 \mathrm{mg} / \mathrm{kg}$ of $\mathrm{MO}$ (Fig. 4D1), the glomerular and tubular

251 architecture were well preserved. They showed negligible amount of granular casting in the renal

252 tubules, similar to that observed in the positive control (Fig. 4E1) group and closely resembles

253 the untreated sham group (Fig. 4A1). Subsequently, scores were awarded to the histology

254 images. Compared to the control group, a substantial elevation in the scores was observed in

255 APAP-treated group (negative control). In contrast, MO (100 mg/kg bw) treated mice scored

256 lower than the APAP-treated group. At $200 \mathrm{mg} / \mathrm{kg} \mathrm{bw}, \mathrm{MO}$ treated group equaled the score of

257 positive control group (Fig. 4F).

258 3.3 MO leaf extract regulates and restores the antioxidant status, in APAP-induced

259 nephrotoxic mice

260 The level of MDA, SOD, CAT and GPx activities in the renal samples are presented in Fig 2.

261 The renal MDA level of APAP group increased significantly $(F=31.63 ; p<0.05)$ to $1.44 \pm$

$2620.17 \mathrm{nmol} / \mathrm{mg}$ of tissue compared with the control group, which was $0.76 \pm 0.13 \mathrm{nmol} / \mathrm{mg}$ of

263 tissue, whereas, the MO $(200 \mathrm{mg} / \mathrm{kg}$ of bw) and silymarin treated groups showed a significant $(F$

$264=30.29,41.6 ; p<0.05)$ decrease in the level of MDA with the values around $0.80 \pm 0.11$

$265 \mathrm{nmol} / \mathrm{mg}$ of tissue (Fig. 2A). Kidney obtained from the mice intoxicated with APAP showed

266 significant decrease in the SOD $(47.17 \pm 5.05 \mathrm{U} / \mathrm{mg}), \mathrm{CAT}(65.83 \pm 5.54 \mathrm{nmol} / \mathrm{min} / \mathrm{mg}$ of

267 protein) and GPx $(2.55 \pm 1.12 \mathrm{nmol} / \mathrm{min} / \mathrm{mg}$ of protein) when compared with control groups

268 showing values of $63.83 \pm 6.00 \mathrm{U} / \mathrm{mg}, 104.27 \pm 5.54$ and $4.25 \pm 0.26 \mathrm{nmol} / \mathrm{min} / \mathrm{mg}$ of protein

269 respectively $(F=8.26,96.29,6.24 ; p<0.05)$. On the contrary, SOD, CAT and GPx activities of

270 the groups treated with MO leaf extract demonstrated a dose-dependent increase, as shown in

271 Fig. 2B-D. At the higher dose (200 mg/kg of bw), MO leaves extract exhibited values of $93.33 \pm$ 
$2725.01 \mathrm{U} / \mathrm{mg}, 92.33 \pm 9.20$ and $7.64 \pm 0.33 \mathrm{nmol} / \mathrm{min} / \mathrm{mg}$ of protein of SOD, CAT and GPx

273 activities respectively, which were significantly $(F=112.84,18.73,12.85 ; p<0.05)$ higher than

274 the APAP-intoxicated mice kidney. The silymarin - (positive control) treated group exhibited

275 SOD, CAT and GPx activity of $63.83 \pm 4.01 \mathrm{U} / \mathrm{mg}, 104.27 \pm 3.41$ and $6.79 \pm 0.16 \mathrm{nmol} / \mathrm{min} / \mathrm{mg}$

276 of protein respectively. However, from Figures $2 \mathrm{~B}$ and $2 \mathrm{D}$, it was clear that treatment with MO

277 leaf extract greatly exceeded the level of SOD and GPx activity compared to the silymarin-

278 treated group. These results indicate that MO leaf extracts effectively restore the antioxidant

279 status of APAP-intoxicated mice kidney.

2803.4 MO leaves extract modulates pro/anti-inflammatory cytokines in APAP-induced 281 nephrotoxic mice

282 To further understand the mechanism of action of MO leaf extract, we evaluated its role in 283 altering the inflammatory cytokines level as displayed in Fig. 3A-D. We also compared these 284 inflammatory changes with the microscopic evidence of granular cast and inflammatory cell 285 infiltrate into the renal tissues (Fig. 4A2-E2). The kidneys of APAP-intoxicated mice showed a 286 significant $(F=24.20,89.71,112.95 ; p<0.05)$ rise in the level of the pro inflammatory 287 cytokines TNF- $\alpha(416.67 \pm 44.93)$, IL-1 $\beta(251.50 \pm 34.18)$, and IL-6 (441.76 \pm 19.98$) \mathrm{ng} / \mathrm{mg}$ of 288 protein, compared to the control group with the values of $132.91 \pm 60.16,28.16 \pm 14.24,219.94$ $289 \pm 18.68 \mathrm{ng} / \mathrm{mg}$ of protein respectively. At the same time, treatment with APAP suppressed the 290 level of anti-inflammatory cytokine IL-10 (131.03 $\pm 31.81 \mathrm{ng} / \mathrm{mg}$ of protein) compared to the 291 control (162.77 $\pm 22.46 \mathrm{ng} / \mathrm{mg}$ of protein). Contrarily, MO leaf extract showed a dose-dependent 292 modulation in the level of these inflammatory markers. Specifically, at $200 \mathrm{mg} / \mathrm{kg}$ of bw, MO 293 leaf extract significantly $(F=15.74,112.73,15.58 ; p<0.05)$ suppressed the level of TNF- $\alpha$ $294(292.50 \pm 60.71)$, IL-1 $\beta(86.22 \pm 21.75)$, and IL-6 $(314.18 \pm 52.76) \mathrm{ng} / \mathrm{mg}$ of protein, and 
295 enhanced the level of IL-10 (215.63 $\pm 12.34 \mathrm{ng} / \mathrm{mg}$ of protein). From Fig. 5A-D, it was clear that

296 the reduction of inflammatory markers in MO treated group exceeded the effects seen in

297 silymarin (positive control) treatment, where the silymarin-treated group exhibited levels of

298 TNF- $\alpha(309.58 \pm 59.61)$, IL-1 $\beta(102.61 \pm 10.13)$, and IL-6 (306.60 \pm 29.82$)$ ng/mg of protein,

299 and the level of anti-inflammatory cytokine IL-10 with a value of $147.69 \pm 12.34 \mathrm{ng} / \mathrm{mg}$ of

300 protein. This was supported by the histology micrographs (Fig. 4B2) of APAP-treated mice,

301 where significant inflammatory cell infiltrate and tubular casting were observed. In the case of

$302 \mathrm{MO}(200 \mathrm{mg} / \mathrm{kg}$ of bw) and silymarin (positive control) treated mice kidney meager/negligible

303 inflammatory cell infiltrate was observed.

\section{4. DISCUSSION}

305 Human and animal bodies contain a certain quantity of trace elements, mostly located in the 306 liver, bones and blood. Enzymes like arginase, mitochondrial superoxide dismutase, 307 cholinesterase, phosphoglucomutase, pyruvate carboxylase and several phosphates, peptidases 308 and glycosyltransferases function with aid of these elements as co-factors (Jarapala et al. 2014).

309 Trace elements are minute in quantity, yet play a vital role in biochemical processes. It has been 310 well established that copper $(\mathrm{Cu})$ and manganese $(\mathrm{Mn})$ are highly known catalytic co-factors for

$311 \mathrm{Cu} / \mathrm{Zn}$-SOD and Mn-SOD antioxidant enzymes that enhances the free-radical scavenging 312 activity, thereby ameliorating the effects of oxidative metabolism. Copper is also necessary for 313 both $\mathrm{Fe}$ and energy metabolism, it also acts as a reductant in the enzymes lysil oxidase, 314 cytochrome oxidase, dopamine hydroxylase, superoxide dismutase (Harris 1992; Dichi et al. 315 2014). In this study, both $\mathrm{Cu}$ and $\mathrm{Mn}$ were found to be highly present in $\mathrm{MO}$ leaf extract 316 compared to the other notable trace elements. However, negligible amounts of toxic elements 317 were found in the MO leaf extract. Nickel (Ni) which has been categorized as a "probable 
318 essential trace element" has also been found in the MO leaf extract. Recent reports indicated that

$319 \mathrm{Ni}$ functions either as a cofactor facilitating the intestinal absorption of the $\mathrm{Fe}^{3+}$ ion, or alters

320 membrane properties and influences oxidation/reduction systems (Samal \& Mishra 2011,

321 Prashanth et al. 2015). In this study, the elemental analysis results of MO leaves show high

322 amounts of Manganese $(\mathrm{Mn})$ and Copper $(\mathrm{Cu})$ and considerable amounts of nickel (Ni) which

323 might involve assisting the enhancement of endogenous antioxidant system to combat APAP

324 nephrotoxicity. The expression of negligible amount of toxic trace elements in MO leaves

325 suggests its safety aspects in biological systems.

326 Acetaminophen (APAP), as the most common and established pain relieving and

327 antipyretic medication on the market, disclose safety breach during overdose and results in

328 hepato-renal damage. The incident rate of APAP hepatotoxicity is higher than renal toxicity,

329 however, recent reports highlighted that renal impairment can be lethal (Eguia \& Materson 1997,

330 Ghosh et al. 2010, Karthivashan et al. 2015b). During APAP overdose, there is saturation of

331 hepatic metabolic pathways and reduced liver clearance of APAP, allowing for higher amounts

332 of the unmetabolized toxic intermediate, N-acetyl-para-amino-benzoquinoneimine (NAPQI), to

333 come into contact with the kidneys. These toxic metabolites are involved in protein arylation,

334 precisely in the S3 segment of the proximal tubule, thereby initiating renal tubular cell death

335 (Tarloff \& Kinter 1997, Bjorck et al. 1988).

336 Elevations in serum creatinine, blood urea nitrogen, sodium, potassium and chloride

337 levels are the most occurring changes seen in APAP-induced nephrotoxicity (Pradhan et al.

338 2013, Sebastian et al. 2007). During renal damage, accumulation of serum urea occurs when the

339 rate of serum urea production exceeds the rate of its clearance; whereas endogenous breakdown

340 of tissue creatine leads to elevation of serum creatinine levels and other electrolytes (Palani et al. 
341 2010). Previous study reports showed that APAP-induced renal damage leads to serum

342 osmolality of $\mathrm{Na}^{+}, \mathrm{K}^{+}$, and $\mathrm{Cl}^{-}$, and was significantly increased at $12 \mathrm{~h}$ and further increased at

$34324 \mathrm{~h}$, which was supposedly due to renal hemodynamic compromise and tubular function

344 impairment (Goddard et al. 2003, Pakravan et al. 2015). Thus the serum concentration of these

345 parameters serves as the most reliable biomarkers of renal dysfunction. In accordance, the results

346 of this study indicated that administration of APAP-inflicted substantial renal damage as

347 evidenced by the elevated levels of serum creatinine, blood urea nitrogen, $\mathrm{Na}^{+}, \mathrm{K}^{+}$, and $\mathrm{Cl}^{-}$.

348 However, mice treated with varying doses of MO leaves extract presented with significantly

349 reduced levels of serum creatinine, blood urea nitrogen, $\mathrm{Na}^{+}, \mathrm{K}^{+}$, and $\mathrm{Cl}^{-}$. The values for these

350 were equivalent or even less than the silymarin (positive control) treated group.

351 This was similar to a previous study report, whereby ethanol extract of Citrus macroptera

352 (EECM) effectively restored the serum biomarkers and electrolytes level, thereby curbing the

353 deterioration caused by alterations of serum $\mathrm{Na}^{+}, \mathrm{K}^{+}$, and $\mathrm{Cl}^{-}$levels in APAP-inflicted renal

354 impairment (Paul et al. 2016). The renal histological results correlate well with the alterations

355 noted in biochemical parameters. The APAP-intoxicated mice revealed severely disorganized

356 glomerulus, dilated tubules, and inflammatory casting, which is in agreement with the previous

357 studies (Hamid et al. 2012, Ahmad et al. 2012), whereas MO leaf extract at a higher dose

$358(200 \mathrm{mg} / \mathrm{kg})$ preserved glomerulus and tubular architecture with insignificant tubular casting,

359 similar to the positive control/sham group. However, the histological findings in APAP-

360 intoxicated mice were at variance with that of Sharifudin et al., 2013 (Sharifudin et al. 2013),

361 where male Sprague-Dawley rats administered $7 \mathrm{~g} / \mathrm{kg}$ body weight of APAP did not reveal any

362 significant changes in kidney histology. The observed variance could be attributed to differences

363 in the doses administered, and animal models (Hook 1993). 

in the kidney tissues, lipid peroxidation (MDA) levels, and activities of the antioxidant enzymes (SOD, CAT and GPx) were measured. During APAP overdose, an imbalance occurs between the formations of ROS and its scavenging mechanism through the endogenous antioxidant system (Hook 1993, Ozbek 2012). This causes an oxidative stress environment, leading to cellular damage via peroxyl radical formation, which is further reorganized through a cyclization process to endoperoxides, and produces malondialdehyde (MDA) as the final product (Yin et al. 2011). In this study the APAP-treated mice showed a significant elevation in MDA levels and substantial decrease in SOD, CAT, and GPx activities, when compared to normal control groups. However, administration of MO leaf extract significantly decreased the levels of MDA and efficiently elevated SOD, CAT, and GPx activities, compared to the APAP-treated group. Our research team has previously reported the existence of flavonoids such as kaempferol, apigenin, quercetin, and multiflorin in the MO leaf extract, which are likely responsible for advancing 377 antioxidant potential.

It was well established that APAP overdose-induced nephrotoxicity occurred via the

379 formation of NAPQI, but some recent reports strongly suggested the role of inflammatory responses in the progression of renal injury (Ghosh et al. 2010, Samal \& Mishra 2011, Ozbek 2012). APAP intoxication induces oxidative stress mediated renal damage, which further triggers a secondary inflammatory cascade associated with cytokine release from Kupffer cells. Proinflammatory cytokines like TNF- $\alpha$, IL-1 $\beta$ and IL-6 are prominently reported in APAP-induced hepato-renal toxicity. They are engaged in massive tubular infiltration of leukocytes, thereby 
387 effective anti-inflammatory activity based on its inhibitory activities against the expression of

388 TNF- $\alpha$ in APAP-intoxicated mice kidney (Ucar et al. 2013). In another study, bazhen decoction

389 was reported to possess some protective role against APAP toxicity through suppression of 390 various pro-inflammatory cytokines, notably TNF- $\alpha$, IL-1 $\beta$ and IL-6 (Song et al. 2014). The 391 results of our study showed elevated levels of TNF- $\alpha$, IL-1 $\beta$, IL-6 in APAP-administered mice 392 kidney, which was significantly suppressed by the MO leaves extract. Anti-inflammatory 393 cytokines such as IL-10 were also produced by the Kupffer cells at the site of tubular 394 inflammation to check this detrimental influence.

Ucar et al. (2013) reported that n-acetylcysteine and ozone therapy also played a renalprotective role in APAP toxicity by significantly elevating IL-10 cytokine level (Ucar et al. 2013). Our results consistently indicated significant suppression of IL-10 cytokine in APAPintoxicated mice, which was effectually restored by MO leaf extract in a dose-dependent manner. Thus MO leaf extract protects the inflammatory-mediated exacerbation of renal damage in APAP-intoxicated mice by modulation of both pro and anti-inflammatory cytokine level. Thus, the postulated overall mechanism of action of MO leaf extract against APAP-induced nephrotoxicity pathway has been clearly elucidated in this study (Fig. 5).

\section{CONCLUSION}

The MO leaf extracts shielded kidney from APAP toxicity through enhancement of the endogenous antioxidant system/ enzymatic level to counteract the oxidative stress environment

407 (ROS). Certain naturally incorporated bioactive constituents, and highly accessible essential trace elements present in MO leaves aided the renal protective activity. The MO leaf extract also exhibited modulatory effect on specific inflammatory cytokines, and aided in combating the 
410 inflammatory cascade associated renal damage seen in APAP toxicity. In the light of 411 biochemical results and histological findings, MO leaf extract can be suggested as a convincing 412 remedy against APAP-induced nephrotoxicity. Thus, further broad translational investigation of 413 these promising protective effects of MO leaves against APAP-induced renal injury may have a 414 substantial influence on developing clinically-feasible strategies to treat patients with renal 415 impairment, or as a supplemental treatment to aid several nephrotoxic drugs on widening of their 416 therapeutic index.

\section{REFERENCES}

Ahmad ST, Arjumand W, Nafees S, Seth A, Ali N, Rashid S, and Sultana S. 2012. Hesperidin alleviates acetaminophen induced toxicity in wistar rats by abrogation of oxidative stress, apoptosis and inflammation. Toxicology Letters 208:149-161. http://dx.doi.org/10.1016/j.toxlet.2011.10.023

Anwar F, Latif S, Ashraf M, and Gilani AH. 2007. Moringa oleifera: a food plant with multiple medicinal uses. Phytother Res 21:17-25. 10.1002/ptr.2023

Aycan IO, Tokgoz O, Tufek A, Alabalik U, Evliyaoglu O, Turgut H, Celik F, and Guzel A. 2015. The use of thymoquinone in nephrotoxicity related to acetaminophen. Int J Surg 13:33-37. 10.1016/j.ijsu.2014.11.020

Bektur NE, Sahin E, Baycu C, and Unver G. 2013. Protective effects of silymarin against acetaminophen-induced hepatotoxicity and nephrotoxicity in mice. Toxicol Ind Health. $10.1177 / 0748233713502841$

Bjorck S, Svalander CT, and Aurell M. 1988. Acute renal failure after analgesic drugs including paracetamol (acetaminophen). Nephron 49:45-53.

Cekmen M, Ilbey YO, Ozbek E, Simsek A, Somay A, and Ersoz C. 2009. Curcumin prevents oxidative renal damage induced by acetaminophen in rats. Food Chem Toxicol 47:14801484. 10.1016/j.fct.2009.03.034

Dichi I, Breganó JW, and Cecchini R. 2014. Role of Oxidative Stress in Chronic Diseases: CRC Press. 
437 Eguia L, and Materson BJ. 1997. Acetaminophen-related acute renal failure without fulminant 438 liver failure. Pharmacotherapy 17:363-370.

439 Ghosh J, Das J, Manna P, and Sil PC. 2010. Acetaminophen induced renal injury via oxidative

440

441

442

443

444

445

446

447

448

449

450

451

452

453

454

455

456

457

458

459

460

461

462

463

464

465

466

467 stress and TNF- $\alpha$ production: Therapeutic potential of arjunolic acid. Toxicology 268:818. http://dx.doi.org/10.1016/j.tox.2009.11.011

Goddard J, Strachan FE, and Bateman DN. 2003. Urinary sodium and potassium excretion as measures of ibuprofen nephro-toxicity. Journal of Toxicology: Clinical Toxicology $41: 747$.

Gowrishankar R, Kumar M, Menon V, Divi SM, Saravanan M, Magudapathy P, Panigrahi B, Nair K, and Venkataramaniah K. 2010. Trace element studies on Tinospora cordifolia(Menispermaceae), Ocimum sanctum (Lamiaceae), Moringa oleifera (Moringaceae), and Phyllanthus niruri (Euphorbiaceae) using PIXE. Biological trace element research 133:357-363.

Hamid ZA, Budin SB, Jie NW, Hamid A, Husain K, and Mohamed J. 2012. Nephroprotective effects of Zingiber zerumbet Smith ethyl acetate extract against paracetamol-induced nephrotoxicity and oxidative stress in rats. Journal of Zhejiang University Science B 13:176-185.

Harris ED. 1992. Copper as a cofactor and regulator of copper,zinc superoxide dismutase. J Nutr 122:636-640.

He Q, Kim J, and Sharma RP. 2004. Silymarin Protects Against Liver Damage in BALB/c Mice Exposed to Fumonisin B1 Despite Increasing Accumulation of Free Sphingoid Bases. Toxicological Sciences 80:335-342. 10.1093/toxsci/kfh148

Hook JB. 1993. Toxicology of the Kidney: CRC Press.

Hörl WH. 2010. Nonsteroidal Anti-Inflammatory Drugs and the Kidney. Pharmaceuticals $3: 2291$.

Isik B, Bayrak R, Akcay A, and Sogut S. 2006. Erdosteine Against Acetaminophen Induced Renal Toxicity. Molecular and Cellular Biochemistry 287:185-191. 10.1007/s11010-0059110-6

Jarapala SR, Kandlakunta B, and Thingnganing L. 2014. Evaluation of Trace Metal Content by ICP-MS Using Closed Vessel Microwave Digestion in Fresh Water Fish. Journal of Environmental and Public Health 2014:8. 10.1155/2014/201506 
468 Karthivashan G, Arulselvan P, and Fakurazi S. 2015a. Pathways involved in acetaminophen 469 hepatotoxicity with specific targets for inhibition/downregulation. RSC Advances 5:6204062051. 10.1039/c5ra07838e

471

472

473

474

475

476

477

478

479

480

481

482

483

484

485

486

487

488

489

490

491

492

493

494

495

496

Karthivashan G, Arulselvan P, Tan SW, and Fakurazi S. 2015b. The molecular mechanism underlying the hepatoprotective potential of Moringa oleifera leaves extract against acetaminophen induced hepatotoxicity in mice. Journal of Functional Foods 17:115-126. http://dx.doi.org/10.1016/j.jff.2015.05.007

Karthivashan G, Tangestani Fard M, Arulselvan P, Abas F, and Fakurazi S. 2013. Identification of Bioactive Candidate Compounds Responsible for Oxidative Challenge from HydroEthanolic Extract of Moringa oleifera Leaves. Journal of Food Science 78:C1368-C1375. 10.1111/1750-3841.12233

Li C, Liu J, Saavedra JE, Keefer LK, and Waalkes MP. 2003. The nitric oxide donor, VPYRRO/NO, protects against acetaminophen-induced nephrotoxicity in mice. Toxicology 189:173-180. http://dx.doi.org/10.1016/S0300-483X(03)00129-X

Mazer M, and Perrone J. 2008. Acetaminophen-induced nephrotoxicity: pathophysiology, clinical manifestations, and management. J Med Toxicol 4:2-6.

Möller-Hartmann W, and Siegers CP. 1991. Nephrotoxicity of paracetamol in the ratmechanistic and therapeutic aspects. Journal of Applied Toxicology 11:141-146. 10.1002/jat.2550110213

Ozbek E. 2012. Induction of Oxidative Stress in Kidney. International Journal of Nephrology 2012:465897. 10.1155/2012/465897

Pakravan N, Shokrzadeh M, Akbari F, and Shadboorestan A. 2015. Effect of a Toxic Dose of Acetaminophen on Electrolytes and Histopathological Changes in the Kidney. International Journal of Clinical Toxicology 2:64-70.

Palani S, Raja S, Naresh R, and Kumar BS. 2010. Evaluation of nephroprotective, diuretic, and antioxidant activities of plectranthus amboinicus on acetaminophen-induced nephrotoxic rats. Toxicol Mech Methods 20:213-221. 10.3109/15376511003736787

Paul S, Islam MA, Tanvir EM, Ahmed R, Das S, Rumpa N-E, Hossen MS, Parvez M, Gan SH, and Khalil MI. 2016. Satkara (Citrus macroptera) Fruit Protects against Acetaminophen- 
497

498

499

500

501

502

503

504

505

506

507

508

509

510

511

512

513

514

515

516

517

518

519

520

521

522

523

524

525

526

Induced Hepatorenal Toxicity in Rats. Evidence-Based Complementary and Alternative Medicine 2016.

Pradhan S, Mandal S, Roy S, Mandal A, Das K, and Nandi DK. 2013. Attenuation of uremia by orally feeding alpha-lipoic acid on acetaminophen induced uremic rats. Saudi Pharmaceutical Journal 21:187-192. http://dx.doi.org/10.1016/j.jsps.2012.03.003

Prashanth L, Kattapagari KK, Chitturi RT, Baddam VRR, and Prasad LK. 2015. A review on role of essential trace elements in health and disease. Journal of Dr NTR University of Health Sciences 4:75.

Samal L, and Mishra C. 2011. Significance of Nickel in Livestock Health and Production. IJAVMS 5:349-361.

Sanz AB, Santamaria B, Ruiz-Ortega M, Egido J, and Ortiz A. 2008. Mechanisms of renal apoptosis in health and disease. $J$ Am Soc Nephrol 19:1634-1642. 10.1681/asn.2007121336

Sebastian MM, Baskin S, and Czerwinski SE. 2007. Chapter 11 - Renal toxicity. In: Gupta RC, ed. Veterinary Toxicology. Oxford: Academic Press, 161-I.

Sharifudin SA, Fakurazi S, Hidayat MT, Hairuszah I, Aris Mohd Moklas M, and Arulselvan P. 2013. Therapeutic potential of Moringa oleifera extracts against acetaminophen-induced hepatotoxicity in rats. Pharmaceutical Biology 51:279-288. 10.3109/13880209.2012.720993

Siddhuraju P, and Becker K. 2003. Antioxidant Properties of Various Solvent Extracts of Total Phenolic Constituents from Three Different Agroclimatic Origins of Drumstick Tree (Moringa oleifera Lam.) Leaves. Journal of Agricultural and Food Chemistry 51:21442155. 10.1021/jf020444+

Song E, Fu J, Xia X, Su C, and Song Y. 2014. Bazhen Decoction Protects against Acetaminophen Induced Acute Liver Injury by Inhibiting Oxidative Stress, Inflammation and Apoptosis in Mice. PLoS ONE 9:e107405. 10.1371/journal.pone.0107405

Tarloff J, and Kinter L. 1997. In vivo methodologies used to assess renal function. Comprehensive Toxicology 7:99-120.

Ucar F, Taslipinar MY, Alp BF, Aydin I, Aydin FN, Agilli M, Toygar M, Ozkan E, Macit E, Oztosun M, Cayci T, and Ozcan A. 2013. The effects of N-acetylcysteine and ozone 
527 therapy on oxidative stress and inflammation in acetaminophen-induced nephrotoxicity 528 model. Ren Fail 35:640-647. 10.3109/0886022x.2013.780530

529 Yin H, Xu L, and Porter NA. 2011. Free radical lipid peroxidation: mechanisms and analysis. Chem Rev 111:5944-5972. 10.1021/cr200084z.

531 


\section{Figure 1 (on next page)}

Modulation of Serum biochemical markers and electrolytes level

Figure 1: Moringa oliefera leaves suppress the detrimental effect of APAP induced nephrotoxicity. A - E represents the level of serum biochemical markers such as creatinine, urea and electolytes such as sodium, potassium and chloride. Values are expressed as the mean \pm SEM of $n=6$ mice in each group. The normality distribution of the data has been confirmed by Shapiro-Wilk test and statistical analysis was performed using one-way ANOVA associated student t-test. $* \mathrm{P}<0.05$ compared to the control group, $\$ \mathrm{P}<0.05$ compared to APAP administered group. Among the treatment groups, when the protection is total (i.e., different from acetaminophen group and relevant to control group) or partial (i.e., different from acetaminophen and control groups) were represented as \# or $¥$ respectively. 

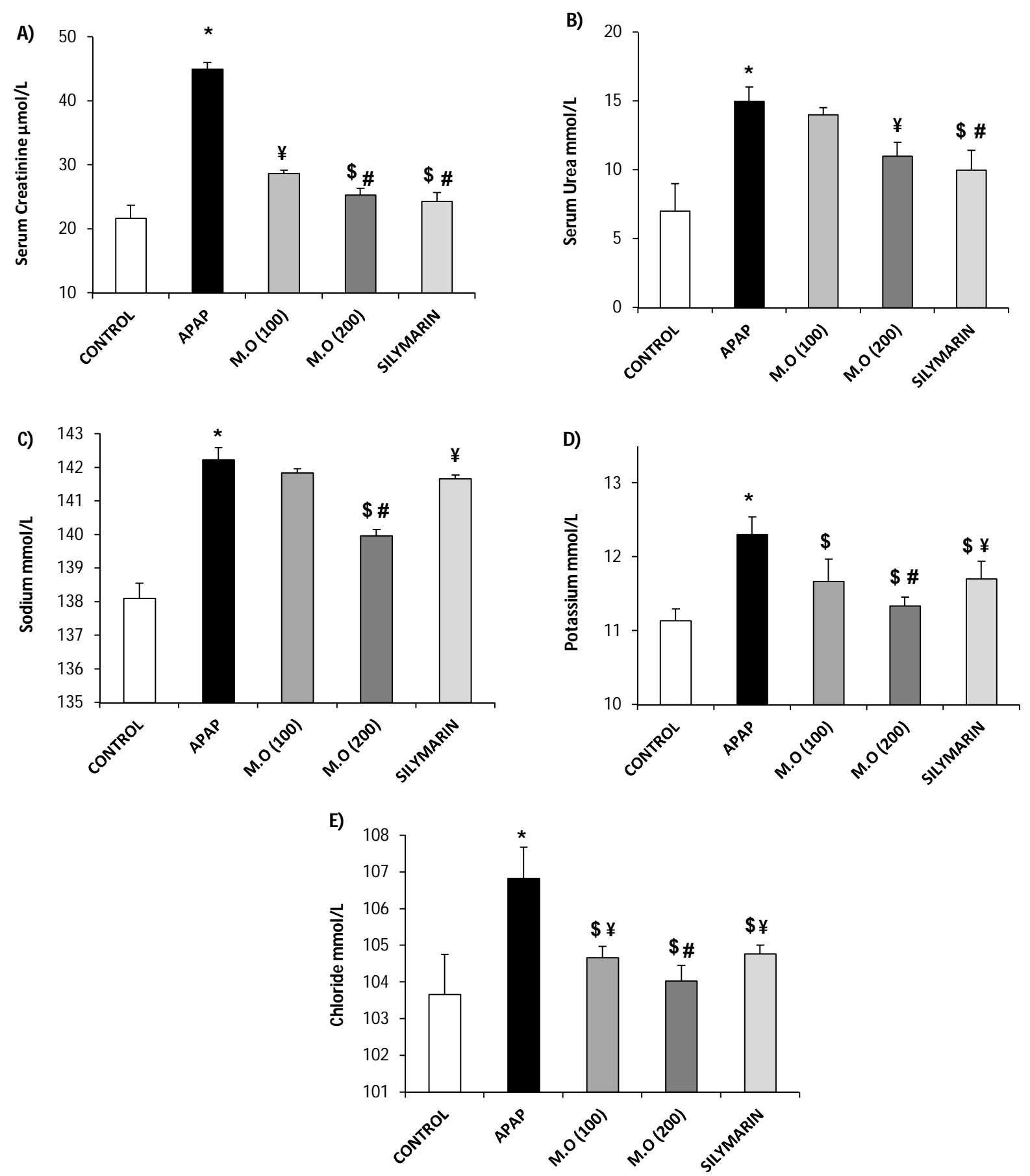


\section{Figure 2 (on next page)}

Level of antioxidant enzymes in kidney tissue

Figure 2: Dose dependent effect of Moringa oleifera (M.O) leaves extract against APAP intoxicated mice kidney via augmentation of endogenous antioxidant status: [A] lipid peroxidation activity (MDA); endogenous antioxidant enzyme levels ([B]-SOD, [C]-CAT\& [D]GPx). Values are expressed as the mean \pm SEM of $n=6$ mice in each group. The normality distribution of the data has been confirmed by Shapiro-Wilk test and statistical analysis was performed using one-way ANOVA associated student t-test. $* \mathrm{P}<0.05$ compared to control group, $\$ \mathrm{P}<0.05$ compared to APAP group. Among the treatment groups, when the protection is total (different from acetaminophen group and relevant to control group) or partial (different from acetaminophen and control groups) were represented as \# or $¥$ respectively. 

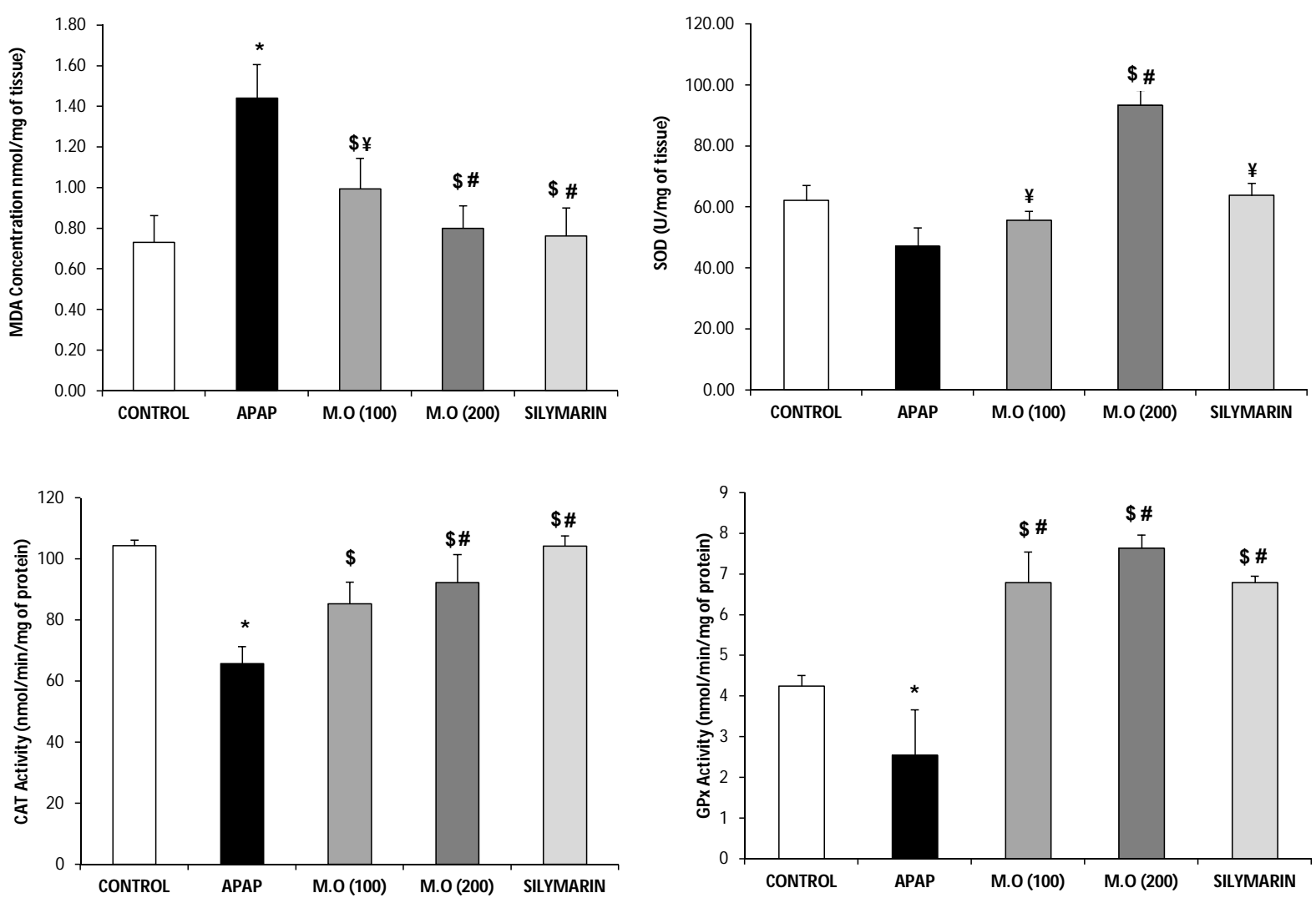


\section{Figure 3 (on next page)}

Alteration in the level of serum inflammatory markers

Figure 3: Modulatory effect of Moringa oleifera (M.O) leaves extract against APAP intoxicated kidney inflammatory cytokines - [A] TNF- $\alpha$; [B] IL-1 $\beta$; [C] IL-6; [D] IL-10. Values are expressed as the mean \pm SEM of $n=6$ mice in each group. The normality distribution of the data has been confirmed by Shapiro-Wilk test and statistical analysis was performed using one-way ANOVA associated student t-test. Results are shown as the mean $\pm \mathrm{SEM}$;* $\mathrm{P}<0.05$ compared to control group, $\$ \mathrm{P}<0.05$ compared to $\mathrm{PCM}$ group. Among the treatment groups, when the protection is total (different from acetaminophen group and relevant to control group) or partial (different from acetaminophen and control groups) were represented as \# or $¥$ respectively. 

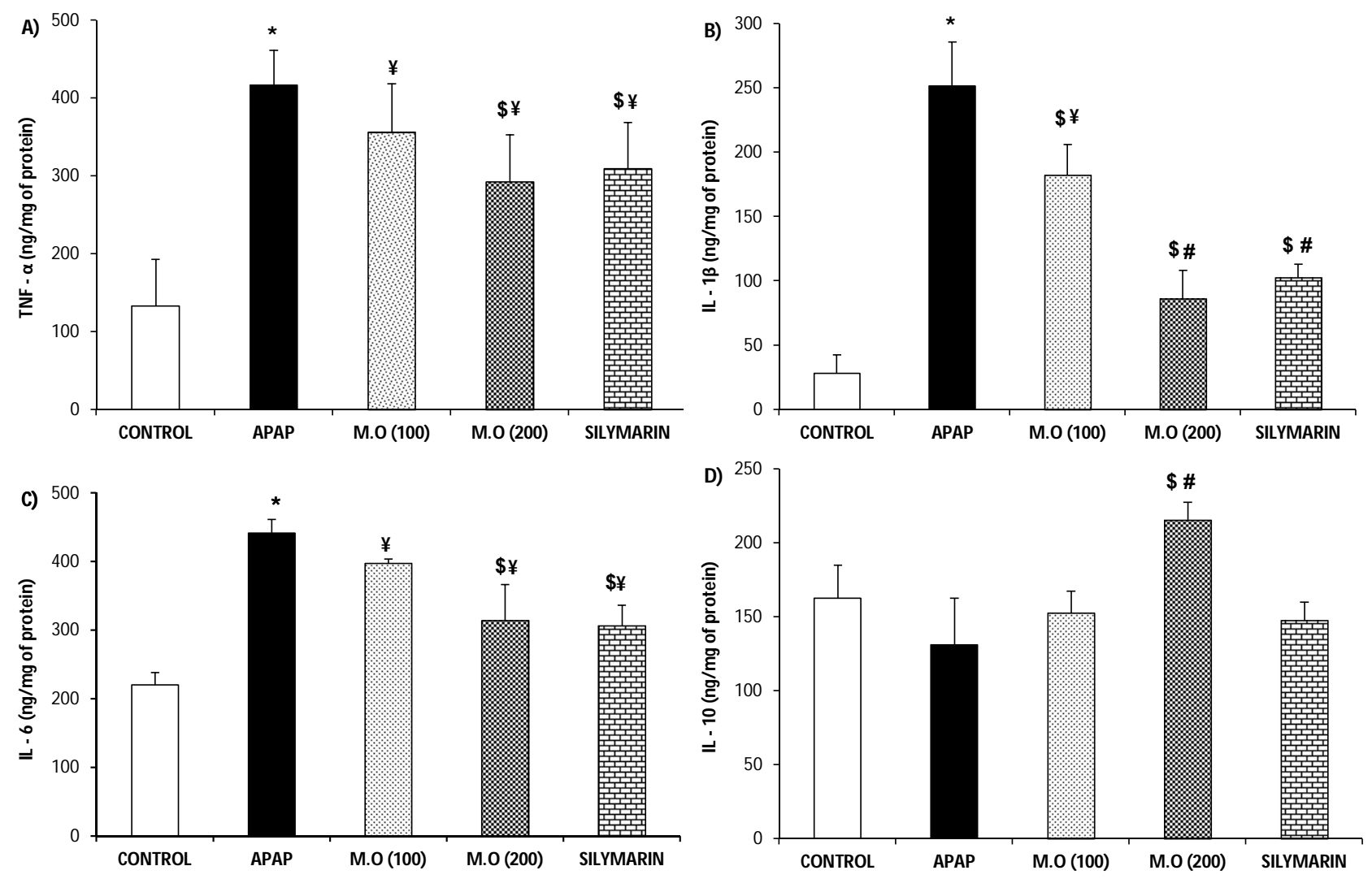


\section{Figure 4 (on next page)}

Photographs of Histopathological modification in kidney tissue

Figure 4: Photographic sections (H\&E 20X - 1; 40X - 2) of the mice kidney, $\mathbf{A}_{\mathbf{1}}$ : Control group showing normal histological architecture of tubules ( $T$ ) and Glomerulus (G) $\mathbf{A}_{2}$ : Flawless tubules with striated border $(\mathrm{T})$, intact glomerulus (arrow) with surrounding Bowman's capsule (line). $\mathbf{B}_{1}$ : Kidney of mice treated with APAP showing disorganized glomerulus (DG), dilated tubules (DT) with tubular casting (C) and inflammation (I) $\mathbf{B}_{2}$ : severely disorganized glomerulus (dotted arrow), tubular dilation (arrow head), and inflammatory casting were observed $\mathbf{C}_{1}$ : Kidney of mice treated with APAP and M.O $100 \mathrm{mg} / \mathrm{kg}$ showing sparsely disorganized glomerulus (DG), dilated tubules (DT) with moderate tubular casting (C) and inflammation (I) $\mathbf{C}_{2}$ : few disorganized glomerulus (dotted arrow) and tubular dilation (arrow head) with tubular casting (C) and inflammation (I) are noticed. $\mathbf{D}_{1}$ : Kidney of mice treated with APAP and M.O 200mg/kg showing preserved glomerulus (G) and tubules (T) architecture with mild tubular casting (C) and inflammation (I) $\mathbf{D}_{2}$ : mild tubular dilation (arrow head) with tubular casting (C) and inflammation (I) are noticed. $\mathbf{E}_{1}$ : Kidney of mice treated with APAP and silymarin (positive control) showing preserved glomerulus $(G)$ and tubules $(T)$ architecture $\mathbf{E}_{2}$ : tubules with striated border (T), intact glomerulus (arrow) are noticed. F: The histological changes were graded as: (-) score (negative score): no any structural damage, $(+)$ score (one positive score): marginal damage, $(++)$ score (two positive score): moderate damage, $(+++)$ score (three positive score): intense damage. 


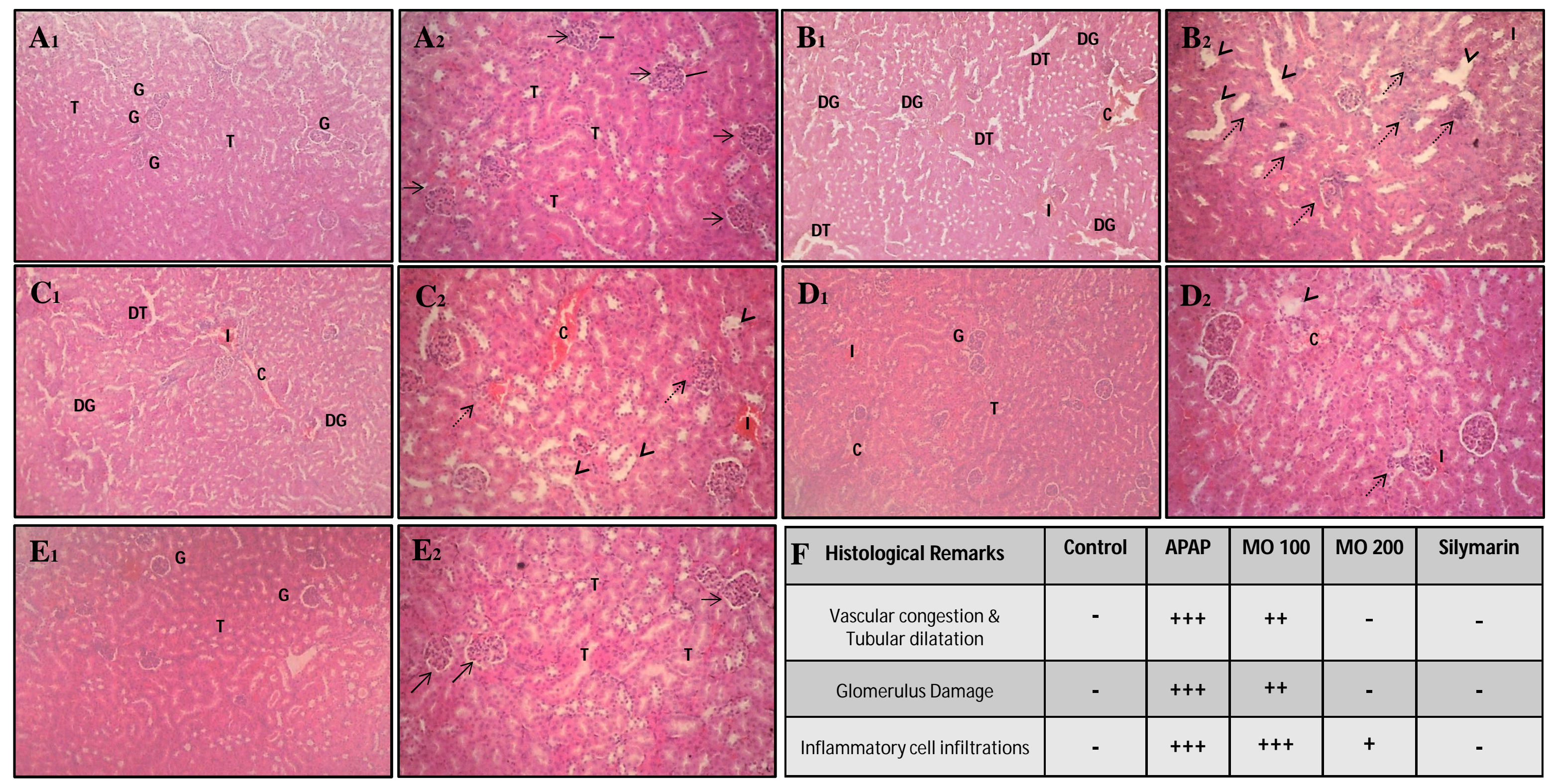


Figure $\mathbf{5}$ (on next page)

Potential mechanism of action of MO leaves extract against APAP induced renal toxicity pathway

Figure 5: Mechanism of action of MO leaves extract against APAP induced renal toxicity pathway: - The active constituents and essential trace elements of MO leaves extract successfully enhance the GSH-GPx and endogenous antioxidant system thereby inhibit the oxidative stress mediated renal impairment, induced by APAP overdose. Despite, MO leaves extract also extensively inhibit the inflammatory cascade by effectual modulation of inflammatory cytokines. Thus curb the further exacerbation of renal injury mediated by inflammatory cytokines. These features evidently project MO leaves extract as a successful nephro-protective agent. 


\section{ACETAMINOPHEN}

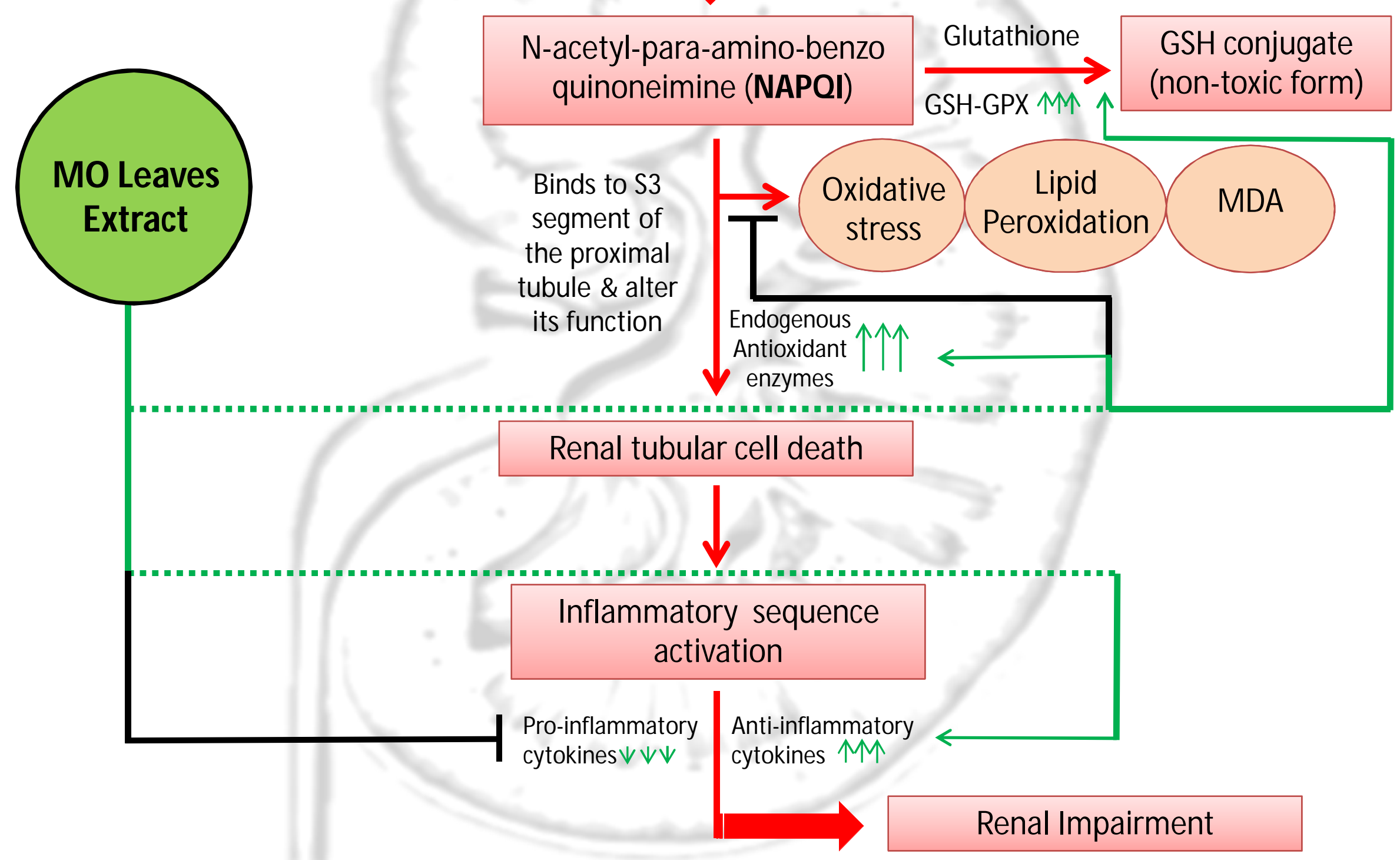

- APAP toxic pathway

— MO extract protective pathway

- MO extract inhibitory pathway 


\section{Table $\mathbf{1}$ (on next page)}

Selective trace element composition of MO leaves

Table.1. Selective trace elemental composition of dried Moringa (M. oleifera Lam.) leaves. 
Table.1. Selective trace elemental composition of dried Moringa (M. oleifera Lam.) leaves.

\begin{tabular}{lll}
\hline Trace elements & $\begin{array}{c}\text { Concentration } \\
\text { (mg/kg of dry leaf } \\
\text { extract) }\end{array}$ & \\
\hline Copper & $12.323 \pm 0.098$ & $\begin{array}{l}\text { a catalytic cofactor in the redox chemistry of free radical } \\
\text { scavenging }\end{array}$ \\
\hline Manganese & $36.157 \pm 0.037$ & $\begin{array}{l}\text { Activator of several manganese metalloenzymes and one } \\
\text { form of antioxidant enzyme superoxide dismutase (SOD). }\end{array}$ \\
\hline Nickel & $1.657 \pm 0.008$ & $\begin{array}{l}\text { Aids in iron absorption, as well as adrenaline and glucose } \\
\text { metabolism, hormones, lipid, cell membrane and improves } \\
\text { bone strength } \\
\text { Chromium (VI) }\end{array}$ \\
\hline $0.005 \pm 0.004$ & $\begin{array}{l}\text { Causes gastrointestinal effects in humans and animals, } \\
\text { including abdominal pain, vomiting, and hemorrhage. }\end{array}$ \\
\hline Lead & $<.005 \pm 0.002$ & $\begin{array}{l}\text { Lead has no known preferred function in the body, but } \\
\text { accumulation of lead is highly toxic for human body. }\end{array}$ \\
\hline Cadmium & $\begin{array}{l}\text { Cadmium is extremely toxic. It mainly affects the kidney, } \\
\text { the cardiovascular system, and is related to cancer. }\end{array}$ \\
\hline
\end{tabular}

